\title{
PEMBUATAN DOSIMETER TERMOLUMINESENSI DARI BAHAN LITIUM FLUORIDA DAN PENGOTOR TITANIUM
}

\author{
Safarudin Hernawan ${ }^{1}$, Eka Djatnika Nugraha S.Si ${ }^{2}$, \\ Dr. Sutanto ${ }^{1}$, Prof. Eri Hiswara ${ }^{2}$
}

1. Program Studi Kimia, Fakultas MIPA, Universitas Pakuan, Bogor, Indonesia

2. Pusat Teknologi Keselamatan dan Metrologi Radiasi, BATAN, Jakarta, Indonesia

\begin{abstract}
ABSTRAK
PEMBUATAN DOSIMETER TERMOLUMINESENSI DARI BAHAN LITIUM FLUORIDA DAN PENGOTOR TITANIUM. Teknologi nuklir bermanfaat dalam berbagai bidang, misalnya bidang energi, pertanian, kedokteran, radiologi, lingkungan, dan lain-lain. Kendati demikian, paparan radiasi dari teknologi nuklir dapat berdampak buruk bagi sel-sel tubuh manusia. Perlu ada pengawasan terhadap pemanfaatan radiasi teknologi nuklir dengan menggunakan alat proteksi radiasi berupa dosimeter personal, yaitu dosimeter termoluminesensi (thermoluminescent dosimeter, TLD) yang saat ini penggunaannya di Indonesia masih diimpor. TLD dapat dibuat dari bahan litium fluorida dengan variasi konsentrasi pengotor titanium $0,04 \%$, $0,06 \%$, dan $0,08 \%$ melalui metode kristalisasi dengan pemanasan pada suhu 950 derajat Celsius selama lima jam. Kristal yang terbentuk dibuat serbuk dan diuji respons, keseragaman, kalibrasi, pemudaran, dan pengulangannya. Hasil percobaan menunjukkan bahwa TLD yang dibuat memiliki respons optimum terhadap radiasi pada konsentrasi pengotor titanium 0,06\%, memiliki faktor kalibrasi sebesar 0,0936, dan dapat diulang pemakaiannya sebanyak 5 kali. Pemudaran TLD yang dibuat sebesar 20\% selama 14 hari.
\end{abstract}

Kata kunci: dosimeter personal, litium fluorida, dosimeter termoluminesensi

\begin{abstract}
DEVELOPMENT OF THERMOLUMINESCENCE DOSIMETER FROM LITHIUM FLUORIDE WITH TITANIUM AS IMPURITY. Nuclear technology is useful in various fields, such as the fields of energy, agriculture, medicine, radiology, environment, and others. Nevertheless, exposure to radiation from nuclear technology could badly affect the human body. One kind of radiation protection is in the form of a personal dosimeter, the most common of which is thermoluminescent dosimeter (TLD). Almost all TLDs in use are imported to Indonesia from foreign countries. In this research TLD was developed from lithium fluoride with titanium impurity concentrations of $0.04 \%, 0.06 \%$, and $0.08 \%$ through crystallization method by heating at $950{ }^{\circ}$ Celsius for five hours. Crystals that were formed were subsequently crushed into powder to undergo response, uniformity, calibration, fading, and repeatability tests. Results showed that the TLD had optimum response to radiation at a concentration of $0.06 \%$ titanium impurities, had a calibration factor of 0.0936 , could be used repeatedly as much as 5 times, and had fading rate of $20 \%$ for 14 days.
\end{abstract}

Keywords: personal dosimeter, lithium fluoride, thermoluminescence dosimeter 


\section{PENDAHULUAN}

Seiring berkembangnya ilmu pengetahuan dan teknologi, pemanfaatan teknologi nuklir pun semakin meluas. Teknologi nuklir berbasis pada pemanfaatan energi yang dibebaskan dari suatu inti atom (nuklida) dalam bentuk radiasi[4]. Pemanfaatan teknologi nuklir mencakup bidang energi, pertanian, kedokteran, radiologi, lingkungan dan industri, dan lain-lain.

Di samping sekian banyak manfaatnya, radiasi nuklir dapat berdampak buruk pada selsel tubuh manusia[2]. Radiasi yang berinteraksi dengan tubuh manusia dapat mengionisasi atau mengeksitasi atom, sehingga radiasi kehilangan sebagian energinya. Energi radiasi yang terserap di jaringan biologis akan muncul sebagai panas yang merupakan awal dari perubahan kimiawi dan kemudian dapat memberikan efek biologis yang merugikan[8].

Karena dapat membahayakan kesehatan, maka pemanfaatan radiasi dan bahan-bahan radioaktif perlu diawasi melalui peraturanperaturan dan badan pengawas yang bertanggung jawab agar peraturan-peraturan tersebut diikuti. Berdasarkan Peraturan Pemerintah Republik Indonesia Nomor 33 Tahun 2007, "perlindungan keselamatan terhadap pekerja radiasi wajib diberikan agar paparan radiasi pengion yang diterimanya tidak melampaui nilai batas dosis yang telah ditetapkan". Oleh sebab itu, dibutuhkan alat proteksi radiasi berupa peralatan pemantauan dosis radiasi perorangan. Saat ini alat proteksi radiasi di Indonesia masih diimpor dari luar negeri. Untuk itu perlu adanya studi pendahuluan untuk membuat alat proteksi radiasi perorangan dalam negeri.

Alat proteksi radiasi dibedakan menjadi tiga jenis, yaitu; surveimeter, dosimeter personal, dan monitor kontaminasi. Dosimeter personal yang banyak digunakan pada saat ini ada tiga macam, yaitu dosimeter saku (pen/pocket dosemeter), film badge, dan dosimeter termoluminesensi (TLD)[9]. Keuntungan dari penggunaan TLD, antara lain; mudah dalam pengoperasian, evaluasi dosis dapat dilakukan dengan cepat daripada dengan dosimeter lain, tidak peka terhadap faktorfaktor lingkungan. Adapun kelemahan TLD adalah data dosis langsung hilang setelah proses pembacaan sehingga tidak bisa dilakukan pembacaan ulang apabila ditemukan hal-hal yang meragukan [1]. TLD tersedia dalam bermacam tipe bahan, di antaranya $\mathrm{Li}_{2} \mathrm{~B}_{4} \mathrm{O}_{7}, \mathrm{LiF}, \mathrm{CaSO}_{4}, \mathrm{CaF}_{2}$ dengan berbagai tipe pengotornya.

\section{TINJAUAN PUSTAKA}

\section{Radiasi}

Radiasi merupakan salah satu cara perambatan energi dari suatu sumber energi ke lingkungannya tanpa membutuhkan medium atau bahan pengantar tertentu. Salah satu bentuk energi yang dipancarkan secara radiasi adalah energi nuklir. Radiasi nuklir memiliki dua sifat yang khas, yaitu tidak dapat dirasakan secara langsung oleh pancaindra manusia dan beberapa jenis radiasi dapat menembus berbagai jenis bahan[9].

Setiap pekerja radiasi wajib memenuhi persyaratan keselamatan radiasi agar dosis paparan radiasi pengionnya dapat dikontrol dan tidak melampaui Nilai Batas Dosis (NBD). Pemantauan dosis dilakukan secara kontinu dengan menggunakan dosimeter yang disesuaikan dengan lingkungan tempat kerja, serta jenis dan laju paparan radiasi yang dimanfaatkan. Hasil pengukuran dosis dan evaluasi dosimeter harus memiliki tingkat keselarasan yang sama. Melalui komite teknis International Electrotechnical Commission (IEC) dan International Organization for Standardization (ISO) telah dirumuskan persyaratan standar internasional untuk dosimeter yang diberlakukan dalam proteksi radiasi[7].

Radiasi pengion merupakan jenis radiasi yang dapat menyebabkan proses ionisasi apabila berinteraksi dengan materi. Jenis radiasi yang termasuk radiasi pengion yaitu partikel alfa $(\alpha)$, partikel beta $(\beta)$, sinar gamma $(\gamma)$, sinar $X$, partikel neutron. Radiasi nonpengion merupakan jenis radiasi yang tidak akan menyebabkan efek ionisasi apabila berinteraksi dengan materi. Radiasi yang termasuk dalam jenis radiasi non-pengion antara lain gelombang radio, gelombang mikro, sinar inframerah, cahaya tampak, sinar ultraviolet[3].

\section{Dosimeter Personal}

Dosimeter personal merupakan alat yang digunakan untuk mengukur dosis radiasi secara akumulatif. Jadi, dosis radiasi yang mengenai dosimeter personal akan dijumlahkan dengan dosis yang mengenai sebelumnya. Dosimeter 
personal harus ringan dan berukuran kecil karena alat ini harus selalu dikenakan oleh setiap pekerja radiasi yang bekerja di medan radiasi [9].

Untuk mengetahui besarnya dosis radiasi yang ditimbulkan, diperlukan suatu sistem dosimeter yang memenuhi persyaratan tertentu, yang dapat mendeteksi dosis radiasi di lingkungan sebesar $1 \mathrm{mGy}$ atau sama dengan Nilai Batas Dosis (NBD) yang diperbolehkan selama satu tahun. Bahkan, sangat dibutuhkan suatu dosimeter yang memiliki kemampuan mengukur dosis radiasi $0,1 \mathrm{mGy}$. Dalam beberapa kasus tertentu, misalnya untuk pemantauan radiasi secara terus-menerus selama satu bulan, diperlukan suatu dosimeter dengan kepekaan 0,01 mGy. Persyaratan lainnya yang penting adalah kemampuan menyimpan informasi dosis radiasi harus tinggi atau kehilangan informasi radiasi selama pemakaian harus kecil. Dosimeter harus tidak terpengaruh oleh kondisi lingkungan seperti kelembapan, suhu, tekanan, dan radiasi bukan pengion. Di samping itu, dosimeter tidak boleh mengandung mineral radioaktivitas alam yang dapat menyebabkan radiasi diri dan sebaliknya dosimeter tersebut mempunyai kesetaraan dengan udara atau jaringan lunak.

Peristiwa luminesensi ada dua macam, yaitu fluoresensi dan fosforesensi. Fluoresensi adalah pancaran cahaya spontan, di mana pancaran akan berakhir jika proses eksitasi yang terjadi pada bahan berakhir, sedangkan pada peristiwa fosforesensi pancaran cahayanya berakhir beberapa saat setelah proses eksitasi pada bahan berakhir[1].

\section{Litium Fluorida}

Lithium Fluorida (LiF) dalam keadaan murni tidak dapat berfungsi sebagai TLD. Dengan penambahan pengotor tertentu dengan konsentrasi tertentu maka LiF mempunyai sifat sebagai dosimeter termoluminesensi, yakni detektor radiasi yang mampu menyimpan radiasi untuk waktu yang lama. Pengotor menyebabkan ketidaksempurnaan di dalam kristal atau biasa disebut cacat kristal. Cacat kristal inilah yang menyebabkan terbentuknya perangkap-perangkap elektron yang akan menyimpan energi radiasi yang mengenai bahan TLD tersebut. Bila suhu sekitar bahan tersebut normal, maka elektron tadi akan terperangkap untuk waktu yang lama, tapi bila kepadanya diberi panas maka elektron akan terlepas dari perangkap dan kembali sebagai luminesen [5].

Jenis TLD dengan bahan utama LiF serta aktivator $\mathrm{Mg}$ dan $\mathrm{Ti}$ (LiF:Mg,Ti atau TLD100) merupakan TLD yang sensitif dan banyak digunakan dalam aplikasi fisika medis, terutama pada pemeriksaan radiodiagnostik [6]. Titanium merupakan logam transisi yang ringan, kuat, tahan korosi, dan srtrukturnya stabil pada suhu tinggi sehingga memiliki ketahanan panas yang baik.

\section{METODE}

Bahan dan alat yang digunakan adalah serbuk litium fluorida dengan kemurnian 90\%, serbuk titanium oksida $\left(\mathrm{TiO}_{2}\right)$, larutan asam fluorida, neraca analitik, aluminium foil, pinset, spatula, krusibel, agate mortal, seperangkat alat-alat gelas, furnace, hot plate, TLD reader Harshaw 3500, sumber radiasi Sr-90 dan Co-60. Semua alat dalam kondisi terkalibrasi dengan baik.

Pembuatan TLD serbuk metode kristalisasi dilakukan dengan mencampurkan 10 gram serbuk $\mathrm{LiF}$ dan serbuk $\mathrm{TiO}_{2}$ dengan variasi konsentrasi $\mathrm{TiO}_{2} 0,04 \%, 0,06 \%, 0,08 \%$, kemudian dilarutkan dengan asam fluorida. Campuran bahan dipanaskan secara bertahap dengan suhu $200{ }^{\circ} \mathrm{C}, 350{ }^{\circ} \mathrm{C}, 650{ }^{\circ} \mathrm{C}$ masingmasing selama 1 jam, kemudian dipanaskan pada suhu $950{ }^{\circ} \mathrm{C}$ selama 5 jam. Setelah kristal terbentuk dihaluskan hingga ukuran 200 mesh. Serbuk TLD di-annealing $400{ }^{\circ} \mathrm{C}$ selama $1 \mathrm{jam}$ dan $200^{\circ} \mathrm{C}$ selama 1 jam. Hal ini dimaksudkan untuk menghilangkan elektron yang berada pada perangkap-perangkap elektron. Serbuk TLD disinari dengan sumber radiasi Sr-90 dengan dosis radiasi 18 mGy pada setiap masing-masing variasi konsentrasi pengotor titanium. TLD yang memberikan respons tertinggi terhadap radiasi dipilih untuk uji selanjutnya. Keseragaman dilakukan dengan cara menyinari 8 TLD yang sebelumnya diannealing dengan dosis radiasi $50 \mathrm{mGy}$ menggunakan sumber radiasi Co-60. TLD yang memiliki pola keseragaman disinari dengan variasi dosis radiasi $5 \mathrm{mGy}, 10 \mathrm{mGy}, 20$ mGy, 25 mGy, dan 50 mGy, lalu dibuat grafik dan ditentukan faktor kalibrasinya. Uji fading (pemudaran) dilakukan dengan menyinari 7 TLD menggunakan sumber radiasi Sr-90 dengan dosis radiasi 12 mGy. Pembacaan dilakukan secara berkala pada setiap TLD. Uji pengulangan dilakukan dengan mengulangi 
proses annealing, penyinaran dan pembacaan sebanyak 5 kali.

\section{HASIL DAN PEMBAHASAN}

Telah dilakukan pembuatan TLD dengan metode kristalisasi yang terbuat dari bahan litium fluorida (LiF) dan titanium oksida $\left(\mathrm{TiO}_{2}\right)$. Pemilihan bahan kristal litium fluorida sebagai detektor radiasi karena merupakan TLD yang sensitif dan memiliki karakteristik bahan yang hampir sama dengan jaringan tubuh manusia, sehingga banyak digunakan dalam aplikasi fisika medis. Penambahan titanium bertujuan untuk meningkatkan sensitivitas dan detektor litium fluorida untuk menyimpan radiasi.

Pada proses kristalisasi, titanium sebagai pengotor akan menyisip di antara struktur kristal litium fluorida sehingga menyebabkan perubahan dalam gap elektron yang terdapat dalam bahan litium fluorida. Gap elektron ini berada di antara pita valensi dan pita konduksi. Litium fluorida merupakan bahan konduktor yang memiliki gap cukup tinggi antara pita valensi dan pita konduksi. Dengan

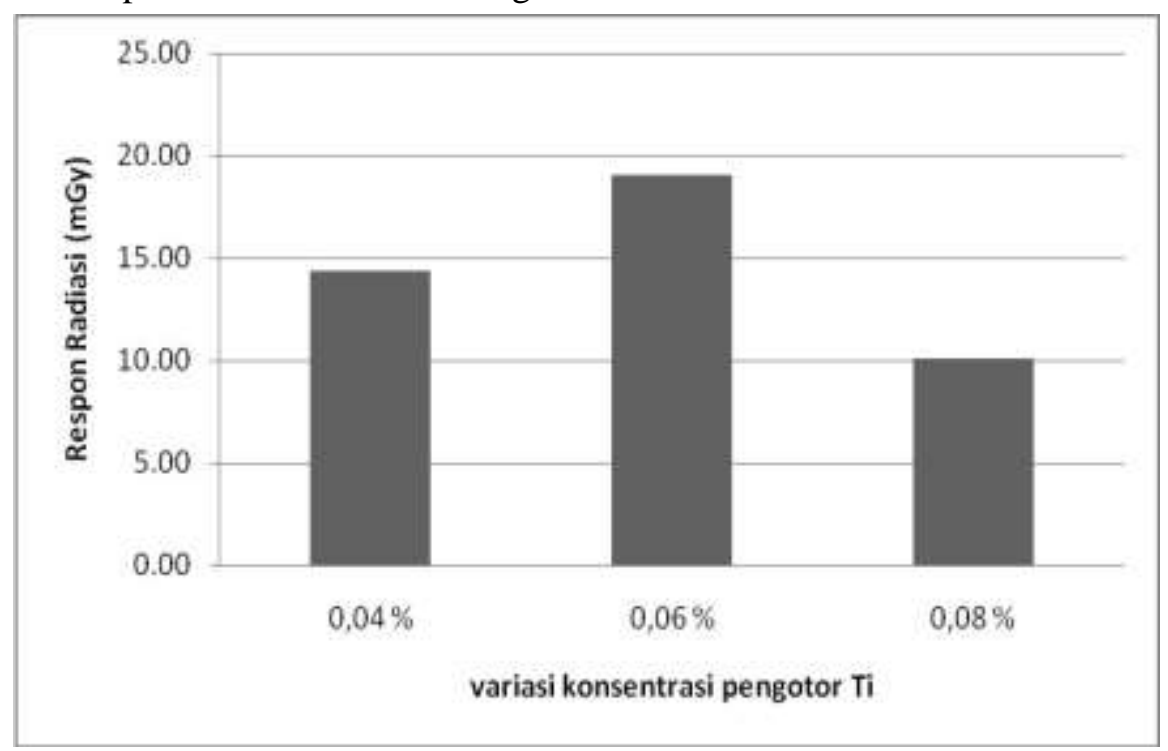

Gambar 1. Hasil Uji Respons Radiasi

Pembacaan optimum serbuk TLD LiF:Ti terjadi pada konsentrasi dopant $\mathrm{Ti} 0,06 \%$, karena memiliki pembacaan respons yang tinggi dibandingkan dengan tingkat konsentrasi lainnya. Serbuk TLD LiF:Ti dengan konsentrasi dopant $0,06 \%$ dipilih untuk pengujian selanjutnya, yaitu uji keseragaman, kalibrasi, fading, dan repeabilitas. ditambahkannya titanium sebagai bahan pengotor atau biasa disebut dopant, maka di antara pita valensi dan pita konduksi akan terdapat susunan lubang yang dapat menyimpan energi. Susunan lubang ini disebut dosimetric trap. Titanium sebagai dopant menjadikan litium fluorida bersifat semikonduktor, yang merupakan bahan yang baik untuk menjadi TLD. TLD merupakan jenis dosimeter personal yang digunakan untuk mengukur dosis radiasi gamma, sinar- $\mathrm{X}$, beta, dan neutron.

Hasil pembuatan TLD LiF:Ti bentuk serbuk dengan variasi konsentrasi pengotor $0,04 \%, 0,06 \%$, dan $0,08 \%$ terlihat sama, tetapi memiliki struktur yang berbeda. Struktur kristal LiF:Ti yang terbentuk dapat dilihat dengan menggunakan XRD (X-Ray Diffraction).

\section{Hasil Uji Respons}

Hasil uji respons terhadap radiasi ketiga variasi konsentrasi dapat dilihat pada Gambar 1. 
konduksi. Akibatnya, perangkap yang tersedia tidak optimal dalam menangkap elektron, maka banyak perangkap yang kosong.

\section{Hasil Uji Keseragaman dan Kalibrasi}

Hasil uji keseragaman pada TLD yang dibuat dapat dilihat pada Tabel 1.

Dipilih 5 TLD yang memiliki tanggapan radiasi yang seragam yaitu TLD yang memiliki tanggapan respons dengan selisih $5 \%$ dari dosis radiasi yang diberikan. Hal ini dikarenakan margin error dari sumber radiasi Cobalt-60 adalah 5\%. TLD yang memiliki pola keseragaman antara lain TLD nomor 1, 4, 5, 6, dan 8. Serbuk TLD yang dipilih diannealing untuk dilakukan kalibrasi.

Hasil pembacaan kalibrasi disajikan dalam bentuk grafik linear pada Gambar 2 .
Tabel 1. Hasil Pembacaan Respons Keseragaman

\begin{tabular}{ccccc}
\multicolumn{5}{c}{ Pembacaan (nC) } \\
\cline { 1 - 4 } Respons \\
(mGy) \\
\hline 1 & TL Total & TL latar & TL bersih & \\
2 & 560,30 & 24,50 & 535,80 & 50,15 \\
3 & 540,20 & 20,80 & 619,40 & 57,98 \\
4 & 540,80 & 12,70 & 558,10 & 52,24 \\
5 & 565,20 & 14,70 & 550,50 & 51,53 \\
6 & 530,30 & 13,20 & 517,10 & 48,40 \\
7 & 510,40 & 17,10 & 493,30 & 46,17 \\
8 & 544,50 & 25,60 & 518,90 & 48,57 \\
\hline \multicolumn{5}{c}{}
\end{tabular}

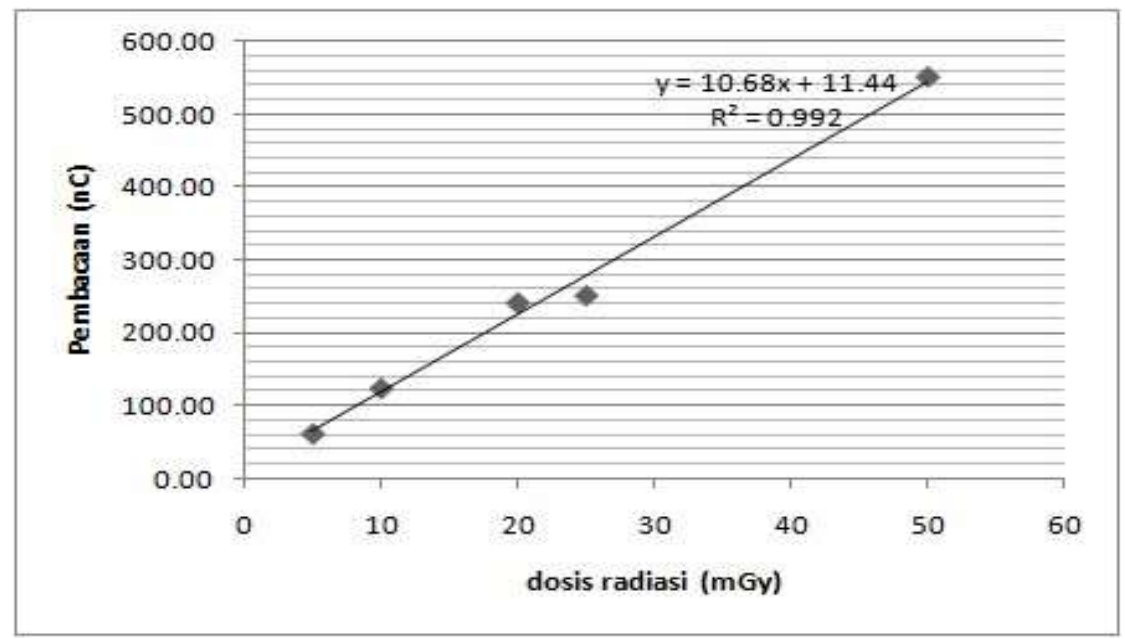

Gambar 2. Grafik Linear Pembacaan Kalibrasi

Hasil dari pembacaan kalibrasi dibuat kurva linear antara dosis radiasi (mGy) dan pembacaan (nC), sehingga didapatkan persamaan $\mathrm{y}=10,68 \mathrm{x}+11,44$, maka faktor kalibrasi untuk TLD LiF:Ti dengan konsentrasi pengotor $0,06 \%$ adalah 0,0936 . TLD yang dibuat memiliki akurasi dan presisi yang tinggi terhadap radiasi karena memiliki nilai $\mathrm{R} 2=0,992$, yang berarti bahwa TLD yang dibuat memiliki linearitas yang baik terhadap beberapa dosis yang diberikan dalam kisaran dosis radiasi 0 mGy hingga $50 \mathrm{mGy}$. Karena syarat TLD yang baik memiliki R2 di atas 0,800, maka TLD LiF:Ti ini layak dijadikan sebagai alat ukur radiasi untuk aplikasi medis dari aspek respons terhadap radiasi.

\section{Hasil Uji Fading dan Pengulangan}

Dalam pemantauan dosis radiasi personal secara rutin, fading merupakan parameter yang dapat mempengaruhi perkiraan dosis. Fenomena fading dapat menyebabkan TLD kehilangan sensitivitas bahan yang terjadi sebelum TLD diradiasi atau kehilangan sinyal setelah TLD diradiasi. Fading pada setiap dosimeter tidak sama, bergantung pada bahan TLD, mekanisme pembacaan, proses annealing, parameter tempat dan lamanya waktu untuk penyimpanan, dan puncak kurva [7]. Hasil pembacaan fading dilakukan selama 14 hari dapat dilihat pada Tabel 2. 
Tabel 2. Hasil Pembacaan Fading Selama 14 Hari

\begin{tabular}{|c|c|c|c|c|c|}
\hline \multirow{3}{*}{$\begin{array}{l}\text { Sampel } \\
\text { (mGy) }\end{array}$} & \multirow{3}{*}{ Hari } & \multirow{2}{*}{\multicolumn{3}{|c|}{$\begin{array}{c}\text { Pembacaan (nC) } \\
\text { Sampel Radiasi }\end{array}$}} & \multirow{3}{*}{$\begin{array}{l}\text { Respons } \\
\text { Radiasi } \\
\text { (mGy) }\end{array}$} \\
\hline & & & & & \\
\hline & & TL Total & TL latar & TL bersih & \\
\hline 1 & 1 & 157.10 & 5.08 & 152.02 & 14.23 \\
\hline 2 & 2 & 141.50 & 6.41 & 135.10 & 12.64 \\
\hline 3 & 8 & 135.80 & 11.25 & 124.55 & 11.66 \\
\hline 4 & 9 & 130.30 & 6.74 & 123.56 & 11.57 \\
\hline 5 & 12 & 142.10 & 12.12 & 129.98 & 12.17 \\
\hline 6 & 13 & 140.10 & 18.51 & 121.59 & 11.38 \\
\hline 7 & 14 & 151.80 & 14.16 & 137.64 & 12.88 \\
\hline & & -rata & & 132.06 & 12.36 \\
\hline & Stanc & deviasi & & 10.66 & \\
\hline
\end{tabular}

Pada Tabel 2 diperlihatkan kemampuan dosimeter dalam menyimpan informasi dosis. Pada proses fading elektron yang berada pada trap yang lebih dangkal akan keluar dengan cepat jika dibandingkan dengan trap yang lebih dalam, karena probabilitas keberadaan transisinya lebih besar. Hasil pembacaan respons radiasi dari uji fading pada hari pertama sebesar 14,23 mGy. Pembacaan respons terkecil terjadi pada pembacaan ke-6 hari ke-13, yaitu 11,38 mGy. Perhitungan besar fading diukur dari selisih pembacaan pertama dan pembacaan ke-6, yaitu sebesar 2,85 mGy, maka nilai fading yang dimiliki TLD LiF:Ti yang dibuat sebesar 20\% selama 14 hari.

Perbandingan nilai fading TLD LiF:Ti dari hasil percobaan berbeda dengan nilai fading TLD LiF referensi, yaitu sebesar 5\% per tahun [10]. Hal ini terjadi karena perangkapperangkap elektron yang terbentuk tidak stabil sehingga terpengaruh oleh faktor-faktor lingkungan seperti pengaruh sinar matahari, suhu ruangan, dan kelembapan. Hal ini menunjukkan TLD LiF:Ti yang dibuat tidak baik dalam aspek fading atau, dengan kata lain, TLD LiF:Ti yang dibuat kurang baik dalam hal menyimpan radiasi.

Penyimpanan dosis radiasi dalam TLD bergantung pada perangkap-perangkap elektron yang terbentuk pada saat pembuatan TLD. Proses pembuatan yang baik memperhatikan suhu dan waktu yang dijaga konstan sehingga proses dopping pengotor pada kristal TLD terbentuk dengan baik, maka untuk mendapatkan hasil fading yang maksimal perlu diperhatikan saat proses pembuatan TLD dengan benar.

Pengulangan dilakukan pada 2 sampel sebanyak 5 kali. Pembacaan terhadap radiasi memiliki respons yang relatif sama. Hal ini menunjukkan TLD yang dibuat dapat diulang pemakaiannya sebanyak 5 kali.

Tabel 3. Hasil Pengulangan Sampel 1

\begin{tabular}{|c|c|c|c|c|}
\hline \multirow{3}{*}{ Repeat } & \multicolumn{3}{|c|}{ Pembacaan (nC) } & \multirow{3}{*}{$\begin{array}{c}\text { Respons } \\
\text { Radiasi (mGy) }\end{array}$} \\
\hline & \multicolumn{3}{|c|}{ Sampel Radiasi } & \\
\hline & TL Total & TL latar & TL bersih & \\
\hline 1 & 158,40 & 14,11 & 144,29 & 13,51 \\
\hline 2 & 156,80 & 19,75 & 137,05 & 12,83 \\
\hline 3 & 151,60 & 16,65 & 134,95 & 12,63 \\
\hline 4 & 153,60 & 14,81 & 138,79 & 12,99 \\
\hline 5 & 154,90 & 17,24 & 137,66 & 12,88 \\
\hline \multicolumn{3}{|c|}{ Rata-rata } & 138,55 & 12,97 \\
\hline \multicolumn{3}{|c|}{ Standar deviasi } & 3,50 & \\
\hline \multicolumn{3}{|c|}{ RSD } & \multicolumn{2}{|c|}{$2,5 \%$} \\
\hline
\end{tabular}

Tabel 4. Hasil Pengulangan Sampel 2

\begin{tabular}{|c|c|c|c|c|}
\hline \multirow{3}{*}{ Repeat } & \multicolumn{3}{|c|}{ Pembacaan (nC) } & \multirow{3}{*}{$\begin{array}{c}\text { Respons } \\
\text { Radiasi (mGy) }\end{array}$} \\
\hline & \multicolumn{3}{|c|}{ Sampel Radiasi } & \\
\hline & TL Total & TL latar & TL bersih & \\
\hline 1 & 172,30 & 3,08 & 169,22 & 15,84 \\
\hline 2 & 163,50 & 3,98 & 159,52 & 14,93 \\
\hline 3 & 183,00 & 16,45 & 166,55 & 15,59 \\
\hline 4 & 170,50 & 9,17 & 161,33 & 15,10 \\
\hline 5 & 174,60 & 11,23 & 163,37 & 15,29 \\
\hline \multicolumn{3}{|c|}{ Rata-rata } & 164,00 & 14,28 \\
\hline \multicolumn{3}{|c|}{ Standar deviasi } & 3,92 & \\
\hline \multicolumn{3}{|c|}{ RSD } & \multicolumn{2}{|c|}{$2,4 \%$} \\
\hline
\end{tabular}

\section{KESIMPULAN}

Telah berhasil dibuat TLD LiF:Ti melalui proses sintering dengan variasi konsentrasi pengotor titanium yang optimum pada $0,06 \%$. TLD LiF:Ti yang dibuat memiliki respons terhadap radiasi yang tinggi dan memiliki faktor kalibrasi 0,0936 $\mathrm{mGy} / \mathrm{nC}$ dengan $\mathrm{R} 2=$ 0,992. TLD LiF:Ti mengalami pemudaran (fading) sebesar $20 \%$ selama 14 hari yang menunjukkan TLD LiF:Ti yang dibuat kurang baik dalam menyimpan informasi dosis radiasi. TLD LiF:Ti dapat diulang pemakaiannya (repeatibilitas) sebanyak 5 kali dengan tanggapan respons yang tinggi terhadap radiasi.

\section{SARAN}

Untuk meningkatkan kualitas TLD LiF:Ti ada beberapa hal yang perlu diperhatikan dalam pembuatan TLD tersebut: 
1. Suhu pada proses pemanasan harus dijaga konstan sehingga pembentukan kristal menjadi sempurna.

2. Perlu penelitian lebih lanjut pada TLD LiF:Ti tentang faktor pengaruh suhu dan waktu aktivasi pembentukan kristal LiF.

3. Perlu penelitian lebih lanjut pembuatan TLd LiF:Ti berupa chip sehingga mudah digunakan sebagai dosimeter perorangan dalam setiap aplikasi medis.

\section{DAFTAR PUSTAKA}

1. Edy, Wahyu Wibowo. 2008. Perbandingan Dosis-Literatur. FMIPA. Universitas Indonesia.

2. Indah, Resti Setyawati. 2012. Model

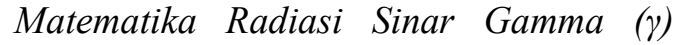
dalam Penentuan Waktu Maksimum Paparan Radiasi Nuklir. Universitas Negeri Papua. Manokwari.

3. Muculus, Mus. 2013. Pengaruh Radiasi Sinar-X Terhadap Mortilitas Sperma pada Tikus Mencit. Universitas Negeri Semarang. Semarang.

4. Irawati, Zubaidah. 2007. Pengembangan Teknologi Nuklir untuk Meningkatkan Keamanan dan Daya Simpan Bahan Pangan. Pusat Aplikasi Isotop dan Radiasi. BATAN. Jakarta.

5. Mutiah. Nurrudin, Ahmad. Gayani, Didi. 2007. Pengaruh Konsentrasi Dopan dan
Temperatur Sinter pada Sensitivitas Dosimeter Termoluminesens LiF:Mg,Dy. PTNBR-BATAN. Bandung.

6. Sofyan, Hasnel dan Dwi, Dyah Kusumawati. 2012. Perbandingan Tanggapan Termoluminesensi LiF:Mg,Ti dan LiF:Mg,Cu,P Terhadap Dosis dalam Aplikasi Medik. PTKMR-BATAN. Jakarta.

7. Sofyan, Hasnel. 2012. Dosimeter Thermoluminensi sebagai Dosimetri Personal dalam Pemantauan Dosis Radiasi Eksternal. Pertemuan Ilmiah XXVI Jateng \& DIY. Purworejo.

8. BATAN. 2008. "Alat Ukur Proteksi Radiasi”. Badan Tenaga Nuklir Nasional. http://www.batan.go.id/pusdiklat/elearnin g/Pengukuran_radiasi [diakses 3 Januari 2015]

9. BATAN. 2008. "Pemanfaatan Nuklir dan Radioisotop dalam Kehidupan Manusia". Badan Tenaga Nuklir Nasional. http://www.batan.go.id/pusdiklat/elearning /proteksiradiasi/pengenalan_radiasi [diakses 4 Januari 2015].

10. Bapeten (Badan Pengawas Tenaga Nuklir). 2003. Keputusan Kepala Badan Pengawas Tenaga Nuklir tentang Sistem Pelayanan Pemantauan Dosis Eksterna Perorangan. Jakarta 